\title{
Research Article \\ Effect of Curing Temperature on the Durability of Concrete under Highly Geothermal Environment
}

\author{
Yang Tang, ${ }^{1}$ Hui Su, ${ }^{2}$ Shun Huang, ${ }^{2}$ Chunlai Qu, ${ }^{2}$ and Jiaqi Yang ${ }^{2}$ \\ ${ }^{1}$ State Key Laboratory of Hydraulic Engineering Simulation and Safety, Tianjin University, Tianjin 300072, China \\ ${ }^{2}$ School of Hydroelectricity, Hebei University of Engineering, Handan 056038, China \\ Correspondence should be addressed to Chunlai Qu; quchunlai@hebeu.edu.cn
}

Received 24 December 2016; Revised 5 April 2017; Accepted 28 May 2017; Published 22 June 2017

Academic Editor: Ying Li

Copyright (c) 2017 Yang Tang et al. This is an open access article distributed under the Creative Commons Attribution License, which permits unrestricted use, distribution, and reproduction in any medium, provided the original work is properly cited.

\begin{abstract}
To determine the durability of concrete in the actual temperature and humidity of the tunnel environment, this study investigates the mechanical properties, permeability of chloride ion, relative dynamic elastic modulus, and mass loss ratio of concrete specimens cured in the temperature which varied from normal, $40,60,75$, and $90^{\circ} \mathrm{C}$, and the humidity was kept at $90 \%$ continuously. Experimental results reveal that the hot temperature curing environment may benefit early stage strength development but reduce the long-term strength. It is proved that $60^{\circ} \mathrm{C}$ is a critical point. At above $60^{\circ} \mathrm{C}$, the strength of the concrete material and its resistance to chloride ion permeability showed a decreasing trend; however, in the appropriate temperature range, the frost resistance properties of the concrete are improved with increasing temperature.
\end{abstract}

\section{Introduction}

During the development of the Western world, mining techniques, and the understanding of underground engineering, gradually improved. The creation of deep strata tunnels in many countries has highlighted the damage that can be caused by highly geothermal environments; these issues are of increasing significance in underground engineering [14]. This damage can seriously affect tunnel construction and durability and can result in changes to the physical behaviour of concrete.

Lee et al. [5] investigated the influence of a hot spring curing environment on the performance of concrete. This study revealed that high temperature environments result in bubbles being more easily produced in concrete. Yan and Cui [6] found that curing temperatures of above $50^{\circ} \mathrm{C}$ significantly stimulate the reactivity of cement, through the grinding of fine slag powder and cement, fly ash, silicon ash composite, and gelled material. Tang et al. [7] investigated the effect of temperature on the adhesion strength of shotcretesurrounded rock and found that increases in temperature led to shotcrete shrinkage and poor bonding performance with hydration products, resulting in more interface pores. The research described above demonstrates that the temperature of the environment affects the bond strength and pore structure of concrete support assemblies during construction and early stages. When a given performance is required, the influence of heat curing on the concrete properties must be considered during the concrete design process, because heat can influence the microstructural and durability properties of the concrete [8].

Nowadays, studies into concrete durability are no longer limited to a single environment but can be performed taking multiple factors into consideration. Jin et al. [9], through experiments using three types of dry and wet circulation systems, determined the deterioration law for concrete under load, carbonation, and exposure to chloride. Holt et al. [10] found that the results obtained from laboratory based, single factor, concrete-accelerated deterioration studies are significantly different from those from exposure, and, for physical test, the combined action of multiple factors should be considered; these studies show that the durability of the material and structure of concrete is affected by the combined action of multiple factors [11]. Multiple factor, concrete durability, research most commonly considers deterioration factors such as freeze-thaw damage, carbonation, and chloride induced corrosion [12]. Freeze-thaw (F-T) action is one of the most aggressive forms of attack on concrete, 


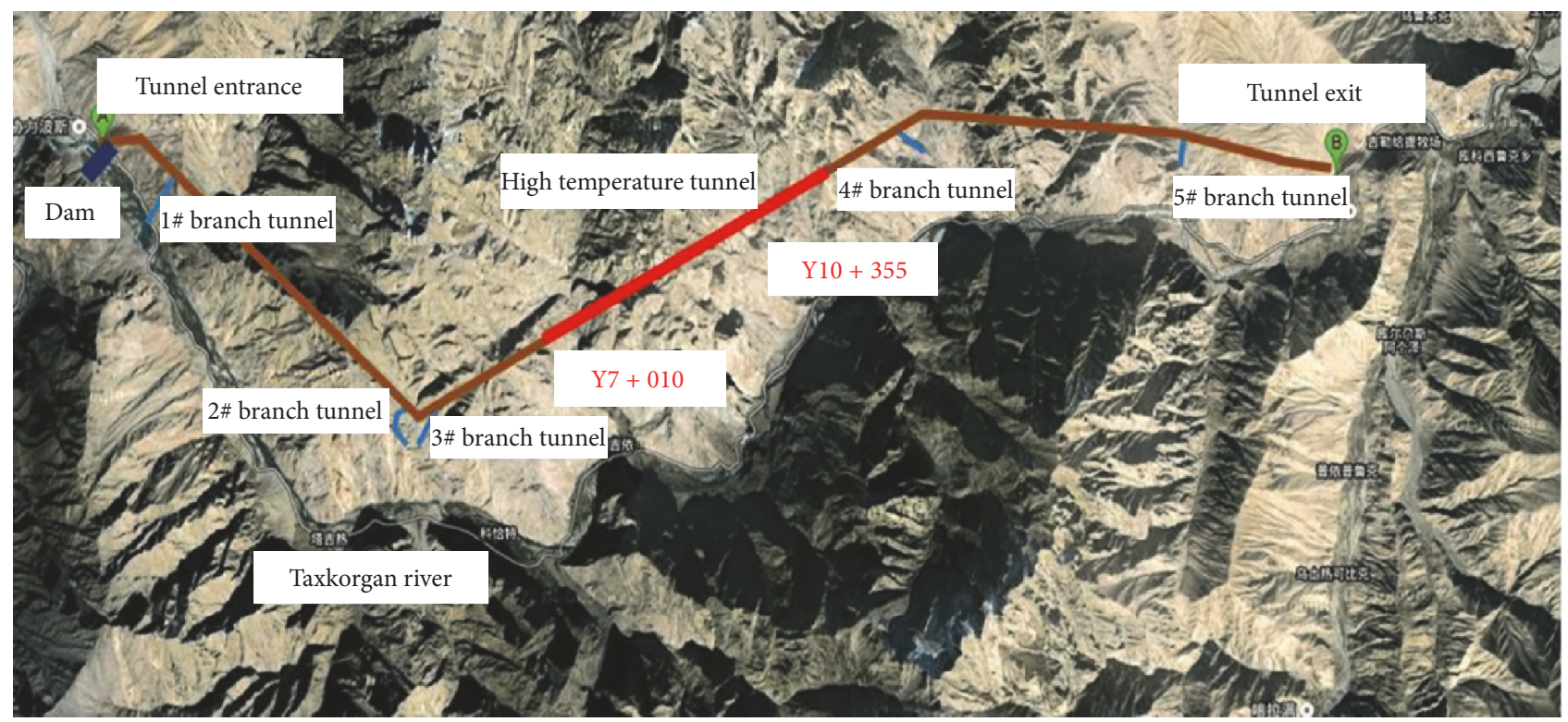

FIgURE 1: Diversion tunnel layout chart.

because F-T cycles can cause serious internal cracking and superficial spalling [13]. It was noted that mechanical freezing and thawing, when coupled with the ingress of deleterious salts, could significantly reduce the longevity of concrete structures [14]. This is because the coefficient of chloride ion diffusivity (CCID) for all concrete increases after exposure to freeze-thaw cycles [15]; thus chloride ion diffusion into the concrete is accelerated [16]. Consequentially, concrete loses its resistance to mechanical loading (i.e., decreases occur in the dynamic elastic modulus and compressive strength).

For the study of chloride ion erosion resistance, Zhang et al. [17] analysed the influence of admixtures on the diffusion of chloride ions in steam-cured and standard concrete. This study showed that, compared to standard concrete, the effect of steam curing on the chloride resistance of concrete is disadvantageous. The chloride ion diffusion coefficient of concrete increases after steam curing, but after addition of a mineral admixture, the chloride ion properties of standard and steam-cured concrete are clearly improved. Wang et al. [18] studied the difference between the durability of shotcrete and ordinary concrete and showed that the addition of steel fibre improves the durability of sprayed concrete, but, against chloride ion erosion, improved performance was not clear.

Based on the above analyses, research into the effects of freeze-thaw cycling and corrosion on accelerated shotcrete has been limited and unsystematic [19]. Currently research work has rarely involved a comprehensive study of the mechanical properties, chloride ion permeability, and antifreeze properties, of concrete under different temperature gradients.

In view of this, and to prevent the corrosion of concrete structures due to temperature, chloride ions, freeze-thaw conditions, or a combination of these factors, this study was performed at normal temperature, 40, 60, 75, and $90^{\circ} \mathrm{C}$, at a relative humidity of $90 \%$. The mechanical properties, permeabilities of chloride ion, relative dynamic elastic moduli, and mass loss ratios were determined in order to better understand concrete durability.

\section{Experimental Investigation}

2.1. Experimental Background. The Qirehataer Hydropower Station is located at the middle and lower reaches of the Tashkur River. The diversion tunnel passes through a highly geothermal environment, between $\mathrm{Y} 7+010$ and $\mathrm{Y} 10+355$ (Figure 1), which was responsible for water vapour gushing into the entrance of the tunnel during construction, owing to the high temperature in the main hole (Figure 2). The tunnel supports made from concrete were curing in high temperature and high humidity environment, which were measured temperature up to $95^{\circ} \mathrm{C}$ and $90 \%$ humidity in the process of construction. In addition, the temperature of the Tashkur River was changed from zero to $12^{\circ} \mathrm{C}$ in the operating period. This is bound to have impact on the strength and durability of concrete.

2.2. Experimental Conditions and Materials. These experimental conditions in this work are based on the actual temperature and humidity of the tunnel environment [7]; consequently the working conditions selected for testing were $\mathrm{RH}$ of $90 \%$ and temperatures of $40,60,75$, and $90^{\circ} \mathrm{C}$ as well as normal temperature (Table 1). The study of concrete durability under these temperature environments was carried out based on the laboratory tests under selected condition. The high temperature curing box is shown in Figure 3.

As shown in Table 2, the raw materials used for the concrete consisted of Taihang cement (strength grade: P.042.5), clean river sand (fineness modulus: 2.70 ), and good-grade crushed aggregate (particle size range: $5-15 \mathrm{~mm}$ ). Additives included HZC-1 accelerating agent, UNF-2A reducing agent, 


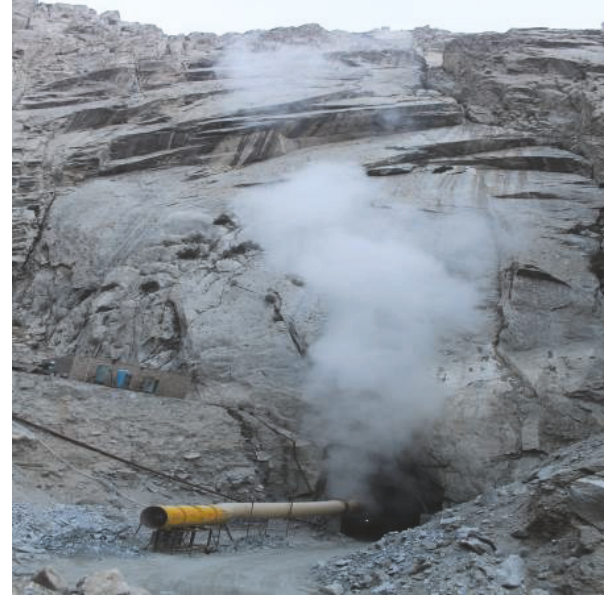

FIGURE 2: Water vapour gushing into the entrance [7].

TABLE 1: Concrete test conditions.

\begin{tabular}{lcccccc}
\hline Test condition & \multicolumn{5}{c}{ Temperature $\left({ }^{\circ} \mathrm{C}\right)$} & Age $(\mathrm{d})$ \\
\hline $90 \% \mathrm{RH}$ & 40 & 60 & 75 & 90 & Normal $(20)$ & $3,7,28$ \\
\hline
\end{tabular}

and RS2000 fibre (Roycele). The mix composition is shown in Table 3.

\subsection{Experimental Setup and Methodology}

2.3.1. The Uniaxial Compression Test. Uniaxial compression tests were carried out on cubic concrete specimens of $100 \mathrm{~mm}$ side length, for 3, 7, and 28 days, following test methodology for the mechanical properties of ordinary concrete (GB500812002, China). A TAW-2000 computer-controlled, electrohydraulic servo rock triaxial testing machine was used for these tests. When the final concrete compressive strength was obtained, it was multiplied by a size conversion factor of 0.95 .

2.3.2. Resistance to Chloride Ion Penetration Test. In this experiment, the resistance to chloride ion penetration test method (RCM) was conducted based on the "Standard Test Method for Long Term Performance and Durability of Ordinary Concrete" (STPDC) of China standard (GBT50082-2009). The size of the mould that was used in this test was $\Phi 100 \mathrm{~mm} \times 50 \mathrm{~mm}$. The specimen was fixed to one end of a silicone rubber sleeve by a hoop, and the side of the cylinder was sealed (Figure 4(a)). The anode plate was placed in the rubber sleeve, and the cathode plate was placed at the bottom of the rubber sleeve (red port is anode and black port is cathode), to which a cathodic solution (10\% wt. $\mathrm{NaCl}$ solution) and an anodic solution $(0.3 \mathrm{~mol} / \mathrm{L} \mathrm{NaOH}$ solution) were added. It should be noted that these solutions should be prepared 24 hours in advance of the experiment and sealed at constant temperature $\left(20 \sim 25^{\circ} \mathrm{C}\right)$. The chloride ion transport coefficient of the concrete was then determined using a chloride ion meter (Figure 4(b)).
The non-steady-state chloride transport coefficient of concrete is calculated as follows:

$$
\begin{gathered}
D_{\mathrm{RCM}}=\frac{0.0239(273+T) L}{(U-2) t}\left[X_{d}\right. \\
\left.-0.0238 \sqrt{\frac{X_{d} L(273+T)}{(U-2)}}\right],
\end{gathered}
$$

where $D_{\mathrm{RCM}}$ is the RCM based on STPDC, in $\mathrm{m}^{2} / \mathrm{s}$; $U$ is the absolute value of the voltage used, in $\mathrm{V}$; $T$ is the average value of the initial and final temperatures of the anode, in ${ }^{\circ} \mathrm{C} ; L$ is the specimen thickness, in $\mathrm{m} ; X_{d}$ is the average chloride ion penetration depth in concrete, in $\mathrm{mm}$; and $t$ is test duration, in h.

2.3.3. Concrete Freeze-Thaw Test. For the concrete freezethaw test, this work used the rapid freeze-thaw method, which was carried out on samples cured for $28 \mathrm{~d}$. The specimen size was $100 \mathrm{~mm} \times 100 \mathrm{~mm} \times 400 \mathrm{~mm}$. A comparison group was set up in accordance with GB-T500822009 "Standard Test Method for Long-term Performance and Durability of Ordinary Concrete." Freeze-thaw analyses were performed every 25 cycles. The maximum number of freezethaw cycles was 100 . The mass and relative elastic modulus of each concrete sample were measured after 25, 50, 75, and 100 freeze-thaw cycles. According to the test method specifications, when the relative dynamic elastic modulus of the specimen dropped to $60 \%$, testing was halted.

\section{Results and Discussion}

3.1. Uniaxial Compressive Strength. The compressive strength values of the concrete at 3,7 , and 28 days are shown in Table 4 .

3.1.1. Influence of Temperature. The compressive strength test results can be divided into three sets of working conditions, namely, 3-day, 7-day, and 28-day curing times. When the curing temperature of the specimen is in the range of around $60^{\circ} \mathrm{C}$, the compressive strength of the concrete gradually increases with increasing temperature. Specifically, when the temperature reached 60 degrees, the concrete test cubes reached the maximum strengths of $34.06 \mathrm{MPa}$, $35.68 \mathrm{MPa}$, and $37.26 \mathrm{MPa}$, for samples cured for 3, 7, and $28 \mathrm{~d}$, respectively. Compared to the data from concrete cured at normal temperature, the strengths measured at $60^{\circ} \mathrm{C}$ showed increases of $43.05 \%, 20.38 \%$, and $15.53 \%$, respectively. However, when the temperature exceeded $60^{\circ} \mathrm{C}$, the strength values began to decrease, indicating that concrete strength is improved only over a certain temperature range, and up to a threshold value. In addition, the compressive strength of the concrete specimens, cured at $60^{\circ} \mathrm{C}$, increases linearly with time, up to $28 \mathrm{~d}$. With increasing temperature, the compressive strength of the concrete decreases, but the overall strength is still higher after $28 \mathrm{~d}$ than at 3 or $7 \mathrm{~d}$ curing ages. These results indicate that temperature does indeed have a significant influence on the compressive strength of concrete, but it is not the only factor to consider. 


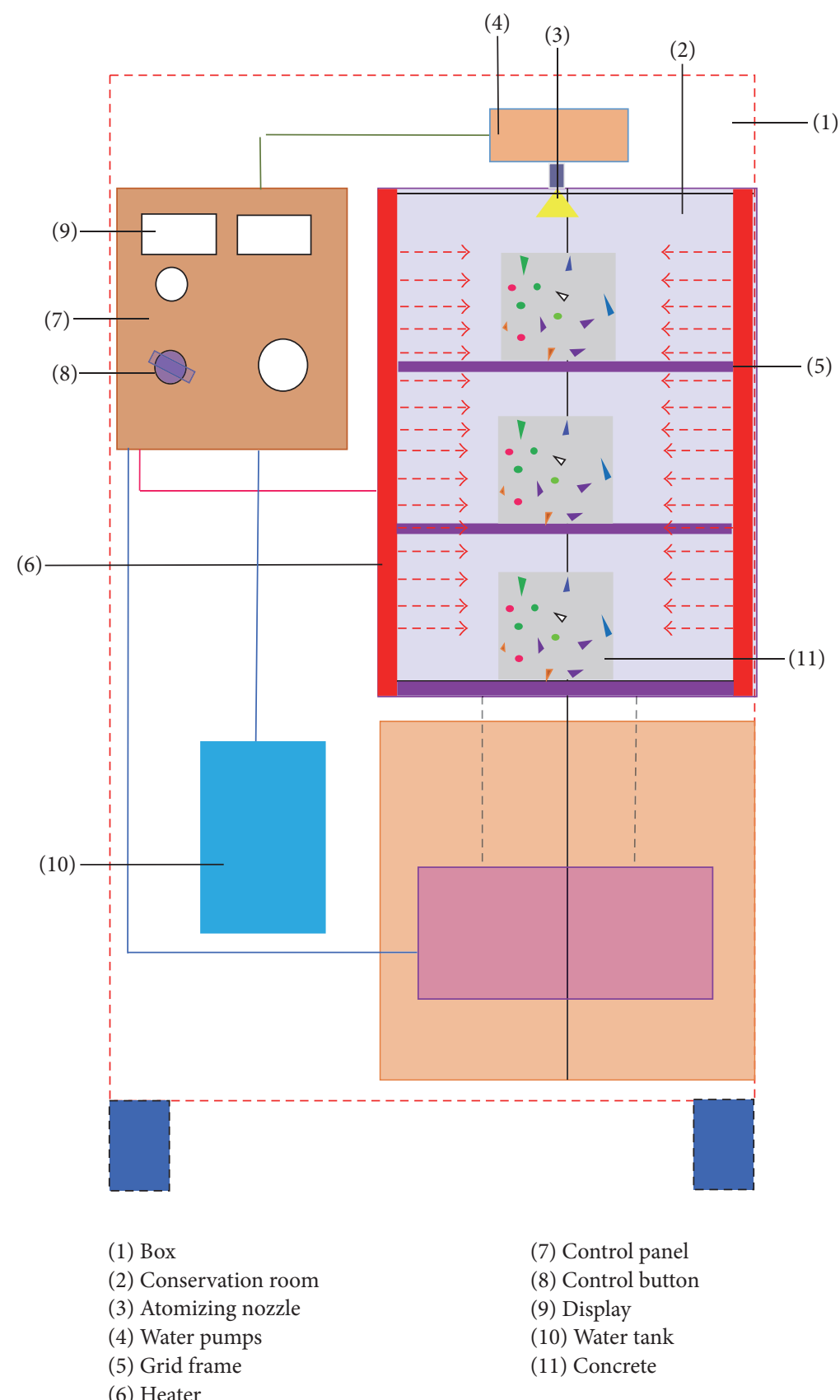

FIGURE 3: The concrete curing room for different temperatures.

TABLE 2: Raw materials for the concrete used in this study.

\begin{tabular}{|c|c|c|c|c|c|c|c|}
\hline Material & Cement & Gravel & Sand & Coal ash & Water-reducer & Accelerator & Fibre \\
\hline Type & P.042.5 & $\begin{array}{l}5-15 \mathrm{~mm} \\
\text { continuous } \\
\text { grading }\end{array}$ & $\begin{array}{l}\text { Machine-made sand, } \\
\text { medium sand with } 2.70 \\
\text { fineness modulus }\end{array}$ & $\begin{array}{l}\text { II with } 18.5 \\
\text { fineness }\end{array}$ & $\begin{array}{l}\text { UNF-2A } \\
\text { naphthalene } \\
\text { type }\end{array}$ & HZC-1 Type & Roycele RS2000 \\
\hline
\end{tabular}

TABLE 3: Experimental concrete mix composition.

\begin{tabular}{lcccccccc}
\hline & \multicolumn{3}{c}{ Material utilization amount $\left(\mathrm{kg} / \mathrm{m}^{3}\right)$} & & & \\
Water-cement ratio & Water & Cement & $\begin{array}{c}\text { Coal ash } \\
(20 \%)\end{array}$ & Sand & Gravel & $\begin{array}{c}\text { Water reducer } \\
(0.7 \%)\end{array}$ & $\begin{array}{c}\text { Accelerator } \\
(4 \%)\end{array}$ \\
\hline 0.42 & 196 & 373 & 93 & 895 & 860 & 3.27 & 18.67 \\
\hline
\end{tabular}




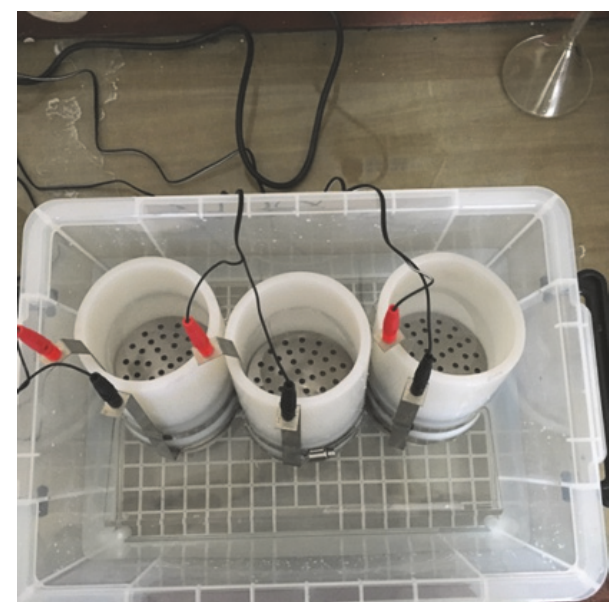

(a) Test device

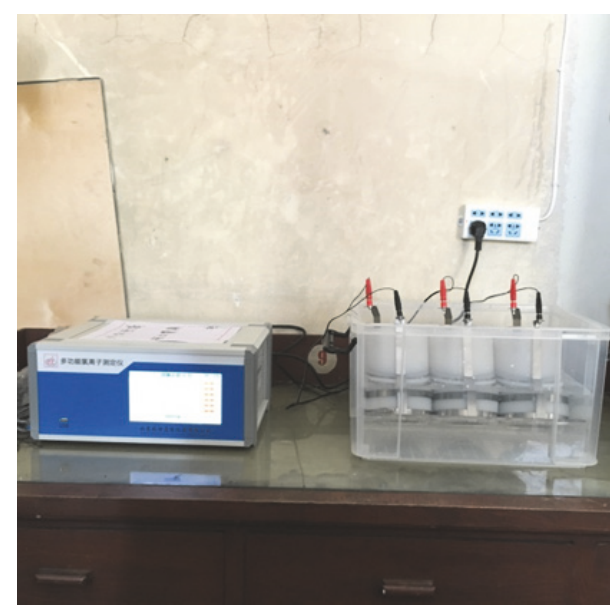

(b) Chloride ion transport coefficient measurement

FIgURE 4: Chloride ion penetration test.

TABLE 4: Compressive strength values for cubic concrete test blocks (MPa).

\begin{tabular}{lcccr}
\hline Temperature & RH\% & $3 \mathrm{~d}$ & $7 \mathrm{~d}$ & \\
\hline Normal & & 23.81 & 29.64 & 32.25 \\
$40^{\circ} \mathrm{C}$ & & 28.71 & 33.06 & 34.73 \\
$60^{\circ} \mathrm{C}$ & 90 & 34.06 & 35.68 & 37.26 \\
$75^{\circ} \mathrm{C}$ & & 26.76 & 27.48 & 28.99 \\
$90^{\circ} \mathrm{C}$ & & 25.11 & 25.19 & 26.91 \\
\hline
\end{tabular}

3.1.2. Influence of Curing Time. At temperatures between 40 and $90^{\circ} \mathrm{C}$, the UCS after 28 days of curing increased by $7.2-35.45 \%$, when compared to the equivalent 3-day sample, and by $4.42-8.80 \%$ when compared to the equivalent 7 -day sample. This indicates that, with increased curing time, the UCS gradually increases under conditions of high humidity. However, the rate of increase relaxes once the curing time exceeds 7 days. This is because, in the high humidity environment, higher temperatures are conducive to improving the rate of the hydration reaction of cement, promoting this reaction and resulting in a rapid rise in strength over the initial curing time. With increasing age, the influence of temperature becomes more and more obvious. The free water in the capillary inside the concrete gradually evaporates and can no longer participate in hydration reactions at later stages. As a consequence, porosity increases and the rate of strength improvement decreases.

3.2. Resistance to Chloride Ion Penetration. The effect of temperature on chloride ion permeability is shown in Figure 5 . It is evident from Figure 5 that $D_{\mathrm{RCM}}$ shows a trend in which it becomes reduced at first but then increases with rising temperature. As the temperature increases but is still lower than $60^{\circ} \mathrm{C}$, the chloride ion migration coefficient of the concrete gradually decreases. However, when the curing temperature exceeds $60^{\circ} \mathrm{C}$, the chloride ion transport coefficient shows an increasing tendency. In particular, when the temperature reaches $75^{\circ} \mathrm{C}$, a sudden increase in this trend becomes apparent. Compared with the ambient temperature

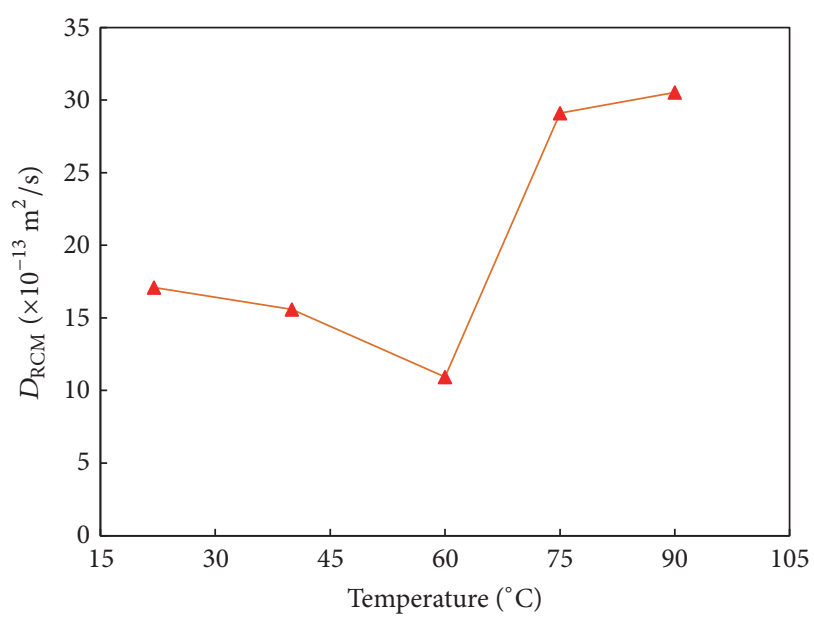

FIGURE 5: Effect of temperature on chloride ion permeability.

environment, the chloride ion migration coefficient increased by $70.28 \%$. Beyond $75^{\circ} \mathrm{C}$, this trend continues until an abrupt increase in the chloride ion migration coefficient is observed at $90^{\circ} \mathrm{C}$. An $\mathrm{AgNO}_{3}$ solution was sprayed onto the surface of the concrete specimens cured at $75^{\circ} \mathrm{C}$ and $90^{\circ} \mathrm{C}$. The surfaces of these specimens exhibit charring (Figure 6). This indicates that the concrete has been eroded by chloride penetration over the specified period of time.

Based on the above analyses, compared with the rest temperatures, we found that concrete cured at $60^{\circ} \mathrm{C}$ has 


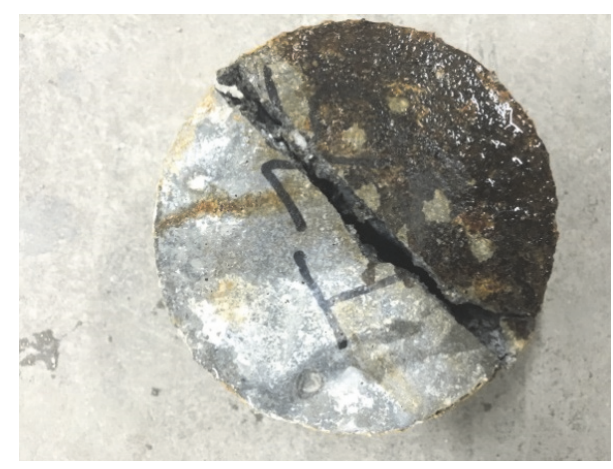

(a) $75^{\circ} \mathrm{C}$

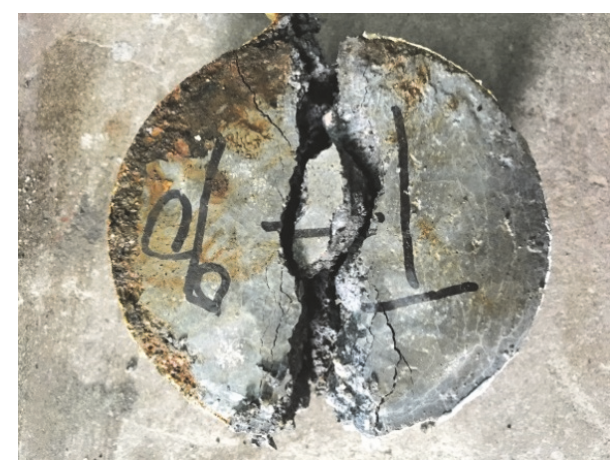

(b) $90^{\circ} \mathrm{C}$

FIGURE 6: Concrete morphology after chloride ion penetration.

the best resistance to chloride ion penetration, because this temperature environment accelerates the rate of concrete hydration, and the formation of the hydrated gel is unable to spread to the concrete surface. This colloid blocks the entry of water and makes the internal hydration reaction incomplete. At the same time, because of the high temperature, the concrete moisture evaporation rate is accelerated, resulting in more porosity cracks in the structure that cause a decrease in the compactness of the concrete.

\subsection{Frost Resistance Property}

3.3.1. Relative Dynamic Elastic Modulus. Figure 7 shows the relative dynamic elastic modulus of concrete specimens under various temperatures. It should be noted that concrete specimens at $75^{\circ} \mathrm{C}$ and $90^{\circ} \mathrm{C}$ are damaged after freezing and thawing to 75 cycles at 28 days (Figure 8). The subsequent tests cannot be continued, and the relative elastic modulus and mass loss data can only be recorded 50 times for the freeze-thaw cycle.

It can be seen from Figure 7 that the relative elastic modulus decreases rapidly at $75^{\circ} \mathrm{C}$ and $90^{\circ} \mathrm{C}$ after 75 freezethaw cycles. After 25 freeze-thaw cycles, the relative elastic modulus of concrete under the curing condition of $75^{\circ} \mathrm{C}$ decreased to $69.78 \%$, and the relative elastic modulus of concrete under the curing condition of $90^{\circ} \mathrm{C}$ decreased to $70.56 \%$. After 50 freeze-thaw cycles, the relative elastic modulus of both the specimens reduced to $65.48 \%$ and $61.04 \%$, respectively. The internal pore structure of concrete determines the frost resistance of concrete, as it is closely related to frost resistance [20]. The initial hydration reaction rate of concrete under curing conditions of $75^{\circ} \mathrm{C}$ and $90^{\circ} \mathrm{C}$ is very fast. The hydrated gel formed mainly on the surface of the concrete specimen and had no time to evenly spread. Furthermore, the presence of colloidal substances blocked the entry of external water into concrete and prevented the hydration reaction to proceed further. In addition, under a high temperature environment, the water loss rate of concrete is faster, which leads to more porosity in the concrete structure and significantly influences the frost resistance of the concrete structure. In the freeze-thaw cycle, freezing and thawing damage the internal structure of the pores, and the

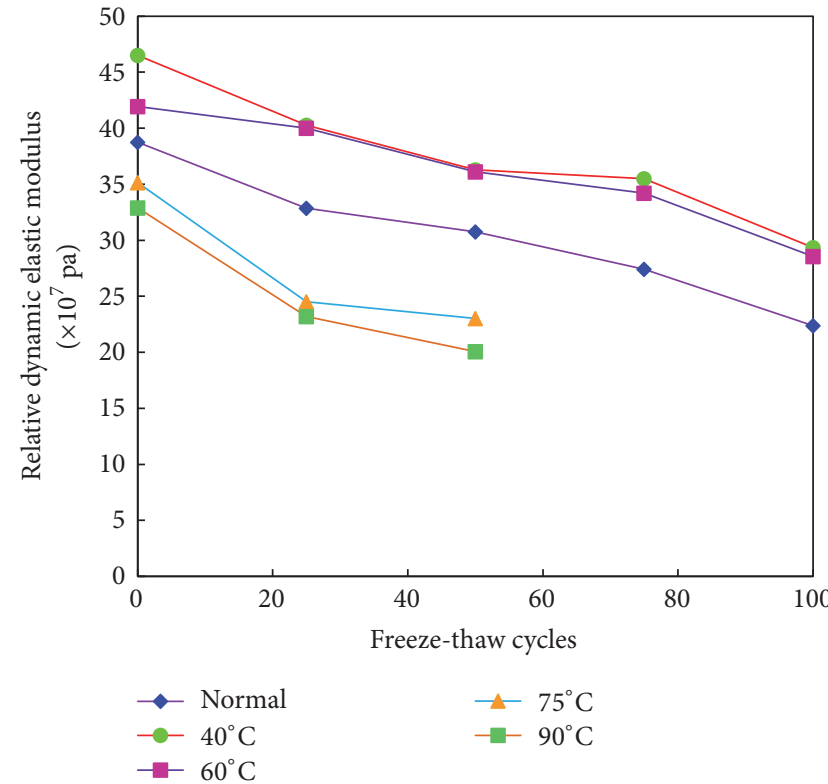

FIGURE 7: Relationship between the number of freeze-thaw cycles and the relative dynamic elastic modulus under different temperatures.

fractured pores interconnect to form larger pores. Owing to this phenomenon, defects in the internal structure of concrete continue to increase. During the freezing process, the ability to resist the cold rise pressure will gradually decrease, eventually leading to the failure of concrete structures. Under the curing conditions of $75^{\circ} \mathrm{C}$ and $90^{\circ} \mathrm{C}$, the resistance of concrete to the coldest pressure is the weaker, so it takes the lead in damaging. Generally, in the process of freezing and thawing, the relative dynamic elastic modulus of concrete firstly reached the failure index.

Compared to the relative dynamic elastic moduli of concrete at $75^{\circ} \mathrm{C}$ and $90^{\circ} \mathrm{C}$, the relative dynamic elastic moduli of concrete at normal temperature, $40^{\circ} \mathrm{C}$ and $60^{\circ} \mathrm{C}$, were $84.85 \%$, $86.80 \%$, and $95.37 \%$, respectively, after 25 freeze-thaw cycles. The relative elastic moduli of the concrete specimens were $79.40 \%, 78.02 \%$, and $86.10 \%$ after 50 freeze-thaw cycles. The results are better than those at $75^{\circ} \mathrm{C}$ and $90^{\circ} \mathrm{C}$. After 100 


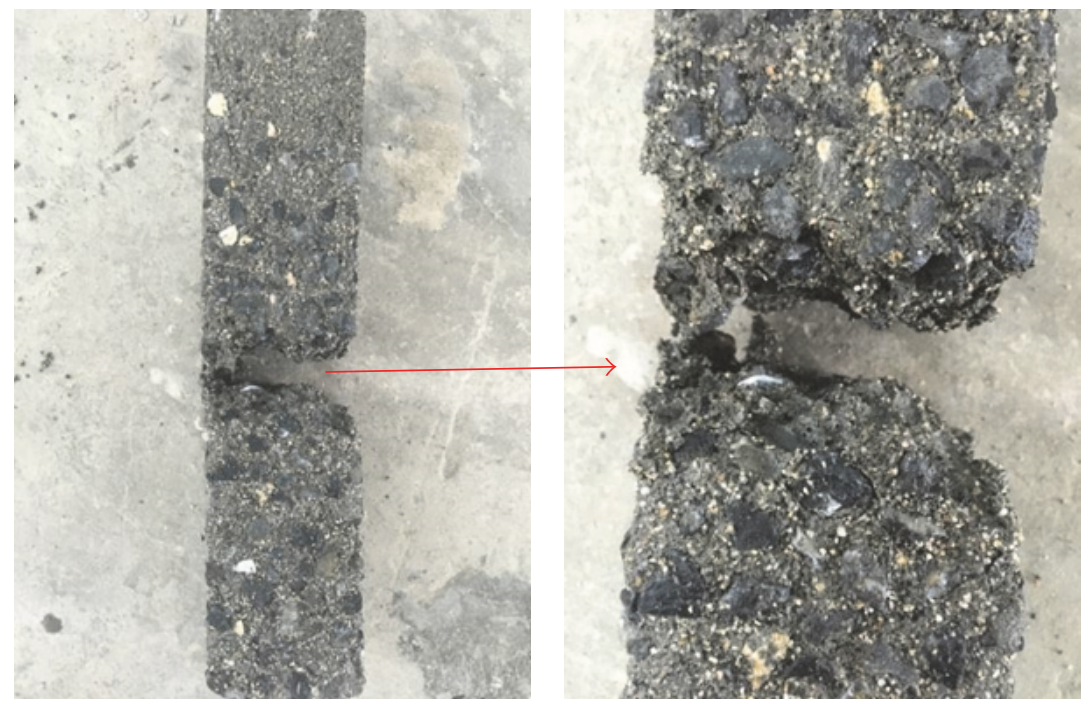

(a) Specimen after 75 freeze-thaw cycles at $75^{\circ} \mathrm{C}$

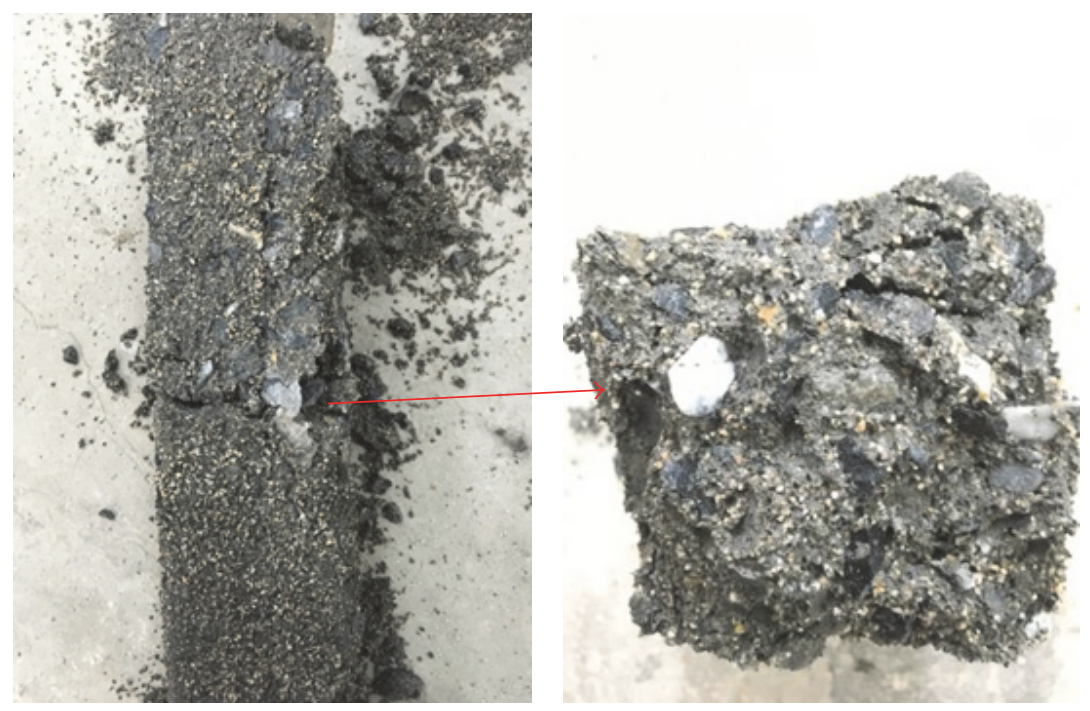

(b) Specimen after 75 freeze-thaw cycles at $90^{\circ} \mathrm{C}$

FiguRE 8: Specimen after 75 freeze-thaw cycles.

freeze-thaw cycles, the relative elastic modulus of the cured specimen under the normal temperature decreases to $57.77 \%$. The relative elastic modulus of concrete specimens at $40^{\circ} \mathrm{C}$ and $60^{\circ} \mathrm{C}$ was $63.08 \%$ and $68.11 \%$ after 100 freeze-thaw cycles. Accordingly, within a certain temperature range, there is a positive correlation between temperature and the ability of the concrete to resist freezing and thawing. The higher the temperature, the better the performance of concrete to resist freezing and thawing. Beyond the certain temperature range, with the increase in temperature, the antifreezing performance of concrete will weaken. A proper curing temperature is advantageous for the concrete hydration reaction, as the reaction can proceed fully. Gel obtained through the hydration reaction can fill the entire internal pore and reduce the number of large pores that is advantageous for improving the antifreezing performance of concrete.
3.3.2. Mass Loss. The quality loss of concrete specimens under different temperatures changes with freeze-thaw cycles, as shown in Figure 9. The quality loss of a standard curing specimen after 100 freeze-thaw cycles is as high as $4.43 \%$. This is because when casting this group of freezingthawing resisting specimens for the steel model test, local damage is caused to the surface of the specimen at the time of mould release. Thus, during the freeze-thaw cycles, parts falling off the surface of the specimen is relatively serious, owing to which the quality loss rate increases rapidly. In order to improve the accuracy of the measurement results, in the following several temperature conditions, all the specimens are poured with detachable steel mould.

As shown in Figure 9, during the later period of freezethaw cycle, the mass loss of specimen at $75^{\circ} \mathrm{C}$ and $90^{\circ} \mathrm{C}$ is larger, only specimens at $75^{\circ} \mathrm{C}$ have a slight mass increase 


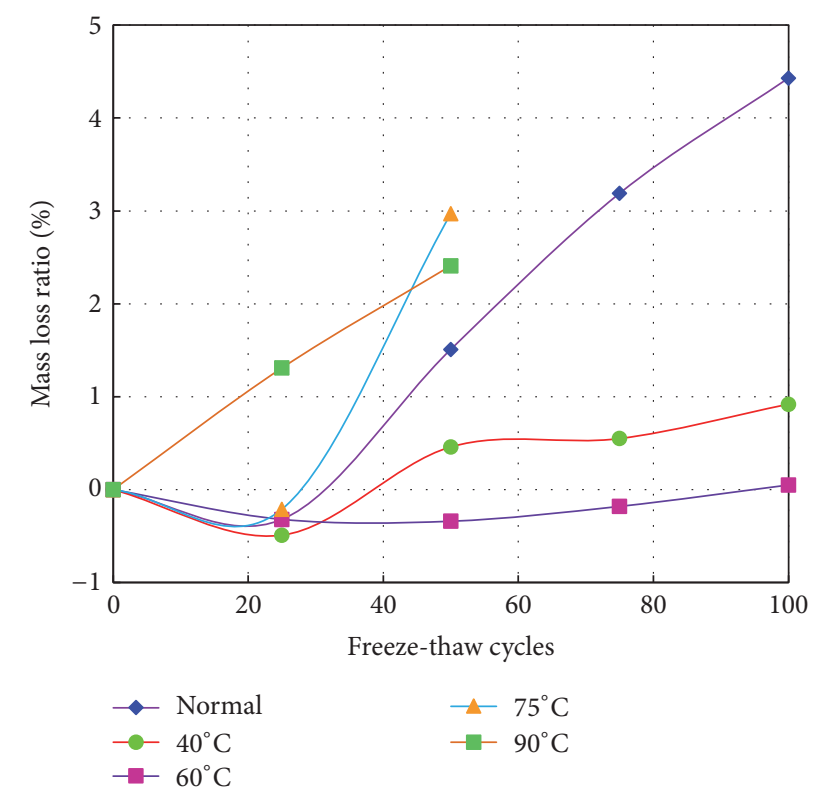

FIGURE 9: Relationship between the number of freeze-thaw cycles and the mass loss ratios under different temperatures.

during the initial period of the freeze-thaw cycle. After 75 freeze-thaw cycles, both specimens break completely, and no further tests are possible (Figure 8). Therefore, the mass loss is measured after 50 freeze-thaw cycles. The maintenance temperature of these concrete specimens under these two conditions has exceeded the optimal curing temperature of concrete under the mix ratio-the hydration gel obtained during the hydration reaction is unable to fill the void inside the pores of concrete, resulting in a lower concrete strength. In the process of freeze-thaw damage, the small pores are less and less while the large pores are increasing. Owing to concrete expansion caused by high temperature curing, the surface of the specimen cracks and peel, and the specimen is more prone to failure during the freeze-thaw cycle. These factors led to the failure of the concrete specimens at $75^{\circ} \mathrm{C}$ and $90^{\circ} \mathrm{C}$ after 75 freeze-thaw cycles, long-term frost resistance requirements. For concrete specimens at $40^{\circ} \mathrm{C}$ and $60^{\circ} \mathrm{C}$, the mass loss rate during the entire freeze-thaw cycle was slower than that for specimens at $75^{\circ} \mathrm{C}$ and $90^{\circ} \mathrm{C}$. After 100 freezethaw cycles, the mass loss rates of concrete specimens at $40^{\circ} \mathrm{C}$ and $60^{\circ} \mathrm{C}$ were $0.92 \%$ and $0.05 \%$, respectively. After 75 freezethaw cycles, the quality of the specimen at $60^{\circ} \mathrm{C}$ increases slightly. However, after 100 freeze-thaw cycles, the quality of the specimen at $60^{\circ} \mathrm{C}$ decreases.

The above results indicate that the quality of the sample showed a downward trend with an increase in the number of freeze-thaw cycles. The mass loss of the concrete specimens at $40^{\circ} \mathrm{C}$ and $60^{\circ} \mathrm{C}$ is the least for 100 freeze-thaw cycles, and their frost resistance is the best. The order of frost resistance of concrete under five temperature conditions is $60^{\circ} \mathrm{C}>$ $40^{\circ} \mathrm{C}>$ normal temperature $>75^{\circ} \mathrm{C}>90^{\circ} \mathrm{C}$. This indicates that a higher curing temperature increases the porosity of concrete and decrease the binding force of concrete. Its frost resistance is worse in comparison. Within an appropriate temperature range, the frost resistance of concrete improves with an increase of temperature.

\section{Conclusion}

In this study, the performance of concrete, including its mechanical properties, permeability of chloride ion, relative dynamic elastic modulus, and mass loss ratio, was investigated to clarify concrete durability under the different temperatures. The following conclusions can be drawn from the study:

(1) Under the condition of high humidity, the early strength of concrete increases obviously with the increase of curing temperature, and the later strength increases little. When the curing temperature is higher than the critical temperature, the concrete strength decreases with the increase of temperature.

(2) The increasing of curing temperature can promote the hydration reaction, which is beneficial to the hardening and integrity of concrete. However, when the temperature is too high, under the action of temperature and hydration heat, the water in the concrete has evaporated in the form of gas, which forms pores or voids, and affects the occurrence of hydration reactions. This results in the decrease of chloride ion resistance and freeze-thaw resistance of concrete. Moreover, concrete durability decreased significantly. An excessively high curing temperature increases the porosity of concrete and decreases the binding force of concrete. In addition, the distribution of hydration products is not uniform. The mass loss of concrete is severe under freeze-thaw cycles. Within an appropriate temperature range, the frost resistance of concrete improves with an increase in temperature.

(3) In the construction process of the concrete supporting system in the high temperature water diversion tunnel, the rock wall temperature and the ambient humidity should be measured in time. When the rock wall temperature is too high, spray cooling and other methods should be taken to reduce the temperature of the rock wall, which can reduce the impact of high temperature on the durability of concrete.

\section{Conflicts of Interest}

The authors declare that they have no conflicts of interest.

\section{Acknowledgments}

The authors would like to acknowledge the support received from Funding research projects in Hebei Education Department (Grant no. QN2015157).

\section{References}

[1] X. W. Hou, X. Q. Li, L. W. Jiang et al., "Estimation of heat-harm of Gaoligong mountain tunnel of Dali-Ruili railway," Journal of Railway Engineering Society, vol. 5, pp. 60-65, 2011. 
[2] S. Krishnaiah, D. N. Singh, and G. N. Jadhav, "A methodology for determining thermal properties of rocks," International Journal of Rock Mechanics and Mining Sciences, vol. 41, no. 5, pp. 877-882, 2004.

[3] X. Q. Li and L. X. Dai, "Cooling technology for construction of high earth temperature section of a diversion tunnel," Water Resources and Hydropower Engineering, vol. 2, pp. 36-41, 2011.

[4] C. S. Yang, "On comprehensive construction technology of high ground temperature tunnel," Railway Construction Technology, vol. 10, pp. 39-46, 2010.

[5] C.-H. Lee, T.-T. Wang, and H.-J. Chen, "Experimental study of shotcrete and concrete strength development in a hot spring environment," Tunnelling and Underground Space Technology, vol. 38, pp. 390-397, 2013.

[6] P.-Y. Yan and Q. Cui, "Effects of curing regimes on strength development of high-strength concrete," Journal of the Chinese Ceramic Society, vol. 43, no. 2, pp. 133-138, 2015.

[7] Y. Tang, G. Xu, J. Lian, H. Su, and C. Qu, "Effect of temperature and humidity on the adhesion strength and damage mechanism of shotcrete-surrounded rock," Construction and Building Materials, vol. 124, pp. 1109-1119, 2016.

[8] J. L. García Calvo, M. C. Alonso, L. Fernández Luco, and M. Robles Velasco, "Durability performance of sustainable self compacting concretes in precast products due to heat curing," Construction and Building Materials, vol. 111, pp. 379-385, 2016.

[9] N. Jin, Y. Xu, C. Fu, X. Jin, and Z. Wang, "Influence of carbonation, chloride attack and loading on concrete deterioration," Journal of the Chinese Ceramic Society, vol. 43, no. 10, pp. 14831491, 2015.

[10] E. Holt, M. Ferreira, H. Kuosa, and M. Leivo, "Performance and durability of concrete under effect of multi-deterioration mechanisms," Journal of the Chinese Ceramic Society, vol. 43, no. 10, pp. 1420-1429, 2015.

[11] H. Pan, Z. Yang, and F. Xu, "Study on concrete structure's durability considering the interaction of multi-factors," Construction and Building Materials, vol. 118, pp. 256-261, 2016.

[12] M. Ferreira, H. Kuosa, M. Leivo, and E. Holt, "Concrete performance subject to coupled deterioration in cold environments," Nuclear Engineering and Design, 2016.

[13] M. Pigeon and R. Pleau, Durability of Concrete in Cold Climates, CRC Press, Boca Raton, Fla, USA, 2010.

[14] Y. Hamze, "Concrete durability in harsh environmental conditions exposed to freeze thaw cycles," Physics Procedia, vol. 55, pp. 265-270, 2014.

[15] C.-W. Chung, C.-S. Shon, and Y.-S. Kim, "Chloride ion diffusivity of fly ash and silica fume concretes exposed to freeze-thaw cycles," Construction and Building Materials, vol. 24, no. 9, pp. 1739-1745, 2010.

[16] J. Zhao, G. Cai, D. Gao, and S. Zhao, "Influences of freeze-thaw cycle and curing time on chloride ion penetration resistance of Sulphoaluminate cement concrete," Construction and Building Materials, vol. 53, pp. 305-311, 2014.

[17] Y. Zhang, H. X. Zhou, G. Cui et al., "Study on the durability properties of steam-cured concrete for subway tunnel segment," Concrete, vol. 7, pp. 119-121, 2010.

[18] J. Wang, D. Niu, and Y. Zhang, "Investigation of mechanical, permeability and durability performance of shotcrete with and without steel fiber," China Civil Engineering Journal, vol. 49, no. 5, pp. 96-109, 2016.

[19] J. Wang and D. Niu, "Influence of freeze-thaw cycles and sulfate corrosion resistance on shotcrete with and without steel fiber," Construction and Building Materials, vol. 122, pp. 628-636, 2016.
[20] P. K. Mehta, The Structural Properties and Materials of Concrete, Tongji University Press, Shanghai, China, 1991. 

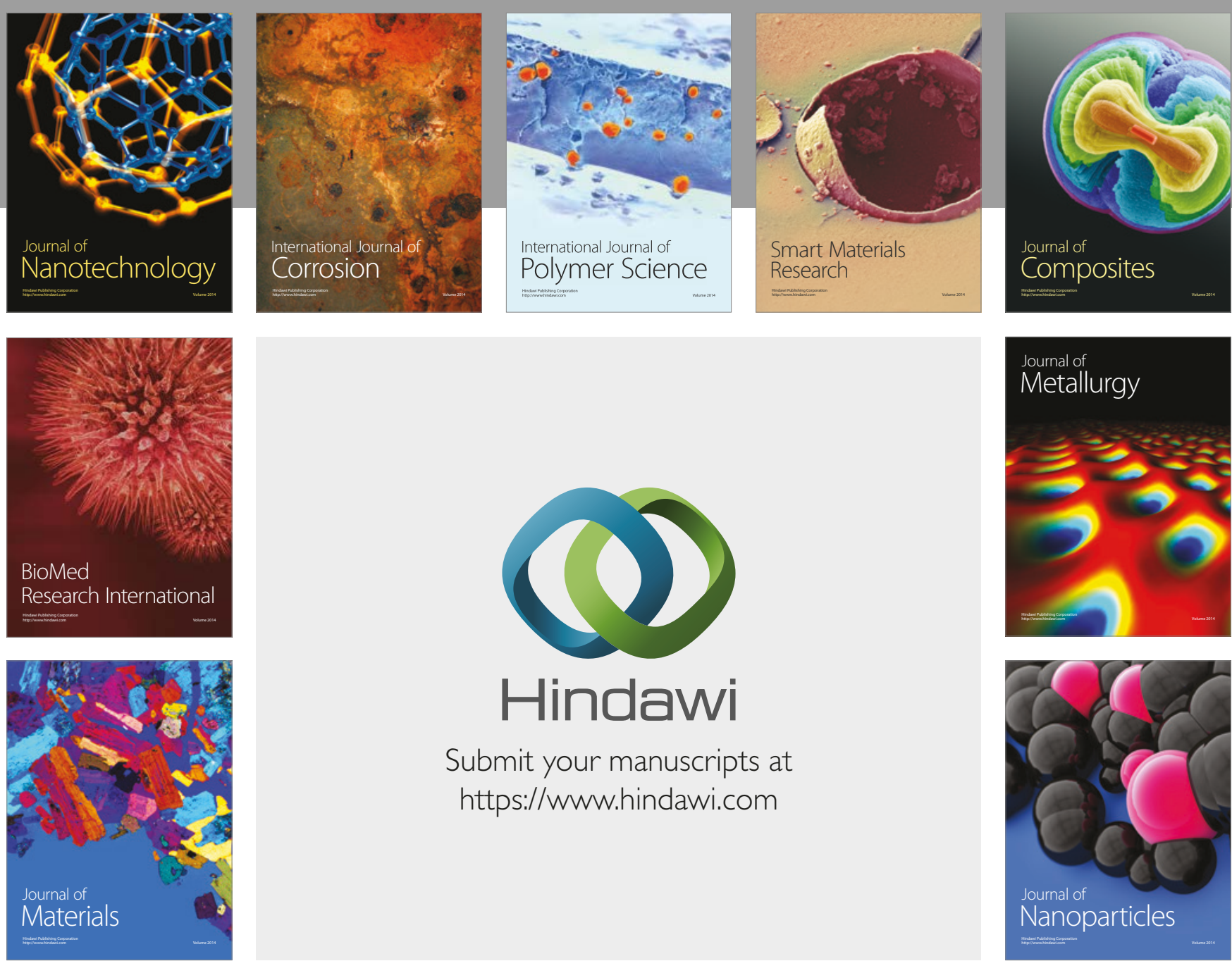

\section{Hindawi}

Submit your manuscripts at

https://www.hindawi.com
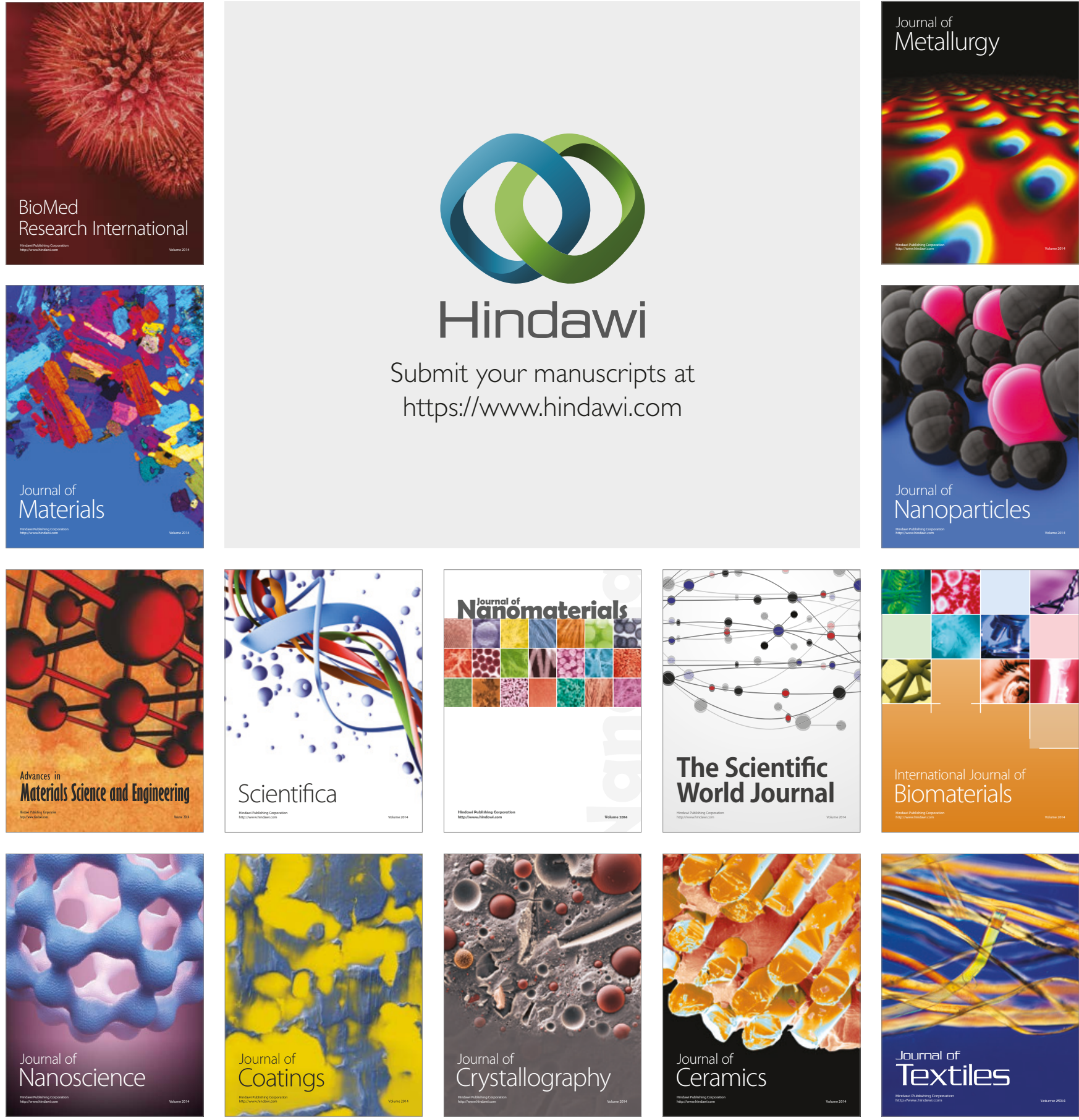

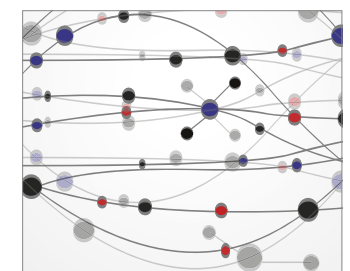

The Scientific World Journal
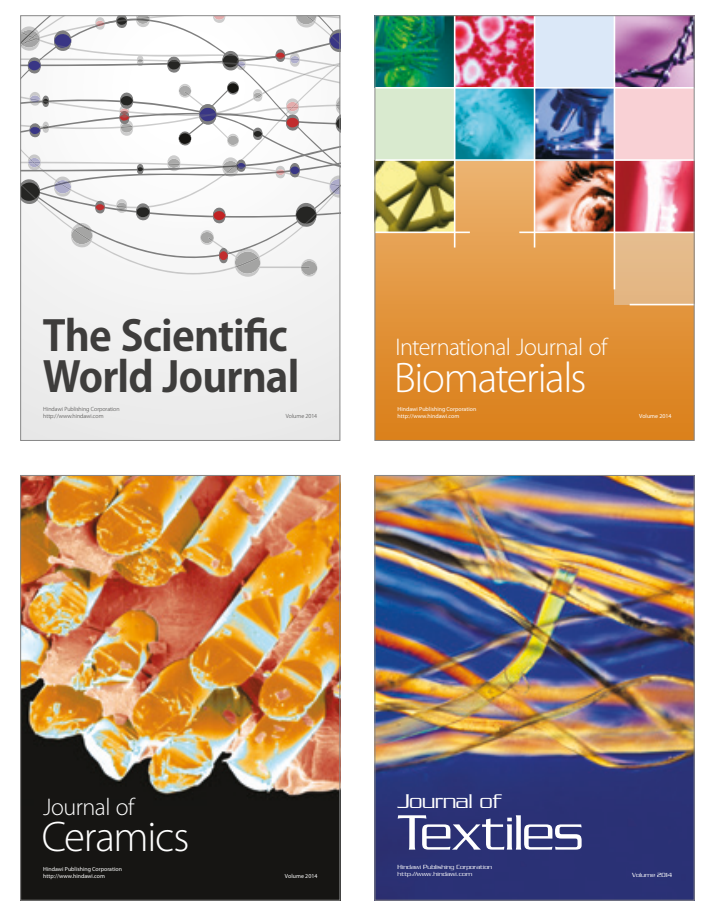